Algumas explosões (e um suspiro): ontologia das imagens digitais na era do neoliberalismo

Fabio Camarneiro ${ }^{1}$

${ }^{1}$ Professor no curso de Cinema e Audiovisual e no Programa de Pós-Graduação em Psicologia Institucional - PPGPSI na Universidade Federal do Espírito Santo - UFES. 


\section{Resumo}

O artigo faz uma crítica à ideia do "fim do cinema" a partir de conceitos ligados ao pós-modernismo (Lyotard, Jameson) e à teoria do cinema (Bazin, Daney, Deleuze). A intenção é mostrar como o neoliberalismo provocou uma mudança na ontologia das imagens, além de certa obsessão pela ideia de "fim" (do cinema e, mais recentemente, das democracias ocidentais). A partir de Deleuze, buscamos entender como a crise do ideal clássico de verdade marca as disputas contemporâneas na política (e na recepção e construção das imagens). Identificamos também, como consequência desse contexto, em $O$ portal do paraíso (Michael Cimino, 1980), o limite de uma forma narrativa específica: o épico.

Palavras-chave: teoria do cinema; imagens digitais; épico; pós-verdade.

\section{Abstract}

This article criticizes the concept of the "end of cinema" based on debates developed from post-modernist (Lyotard, Jameson) and French film theory (Bazin, Daney, Deleuze). My intention is to show how Neoliberalism has changed the ontology of the images and also how it is obsessed with "ends" (the end of cinema and, more recently, of western democracies). The article tries to understand how the crises of the "classical ideal of truth" (Deleuze) is shaping both the contemporary political disputes and the imagery reception and construction in the contemporary world. It is also noted, as consequence of all these elements, how Heaven's Gate (Michael Cimino, 1980) deals with the limits of one specific narrative genre: the epic.

Keywords: Film Theory; Digital Image; Epic; Post-Truth 
This is the way the world ends

This is the way the world ends

This is the way the world ends Not with a bang but a whimper.

- T. S. Eliot,

"The Hollow Man"

Antes de começar, é preciso decidir: o que teria chegado ao fim (se é que algo efetivamente chegou)? O título do livro de Gaudreault e Marion (2016) é elegante ao não abrir mão do ponto de interrogação: O fim do cinema?. Mais taxativos, o diretor Peter Greenaway chegou a decretar a morte do cinema (COONAN, 2007), enquanto Dixon elencou 25 razões para justificar "why it's all over" (DIXON, 2001: 356).

Em algum ponto intermediário, nem exatamente apocalíptico (a lamentar as recentes mudanças na experiência da espectatorialidade e a progressiva escassez das projeções em filme, cada vez mais restritas a cinematecas e outros espaços de preservação), nem exatamente integrado (a celebrar essas mesmas mudanças como algo inerentemente emancipatório), acreditamos que o cinema — se entendido de maneira ampla — ainda não atingiu seu limite.

Mas o que talvez tenha chegado a termo seja o futuro do cinema. Em outras palavras, a inexistência (e talvez a impossibilidade) de uma formulação teórica que possa resolver seus impasses contemporâneos, relacionados à lógica do neoliberalismo.

\section{Fim de uma épica? (Fim de uma época?)}

Uma série de autores, ao menos desde o final da década de 1970, tem percebido como a ideia do "fim" ronda o pensamento contemporâneo. Segundo Berardi, "o futuro morreu" em 1977, quando "mudam de perspectiva e de significado todos os rituais coletivos: a política, a espiritualidade e a música adquirem um sentido apocalíptico que não encontra uma linguagem adequada para se expressar" (BERARDI, 2019: 88). Assim, estariam em crise tanto a ideia de futuro quanto - como veremos a partir do filme O portal do paraíso (Heaven's Gate, 1980), de Michael Cimino - a representação do passado. Como se a falta de perspectivas à frente impedisse que a história (ao menos a grande histoire) encontre lastro em sua representação.

Não por acaso, apenas dois anos após a "morte anunciada" do futuro (segundo Berardi), Lyotard definiu o "pós-moderno" como "a incredulidade em relação aos metarrelatos" (LYOTARD, 2009: xvi). Assim, se entendermos a própria ideia de futuro como um metarrelato, podemos reunir Berardi e Lyotard e assim depreender que essa 
grande narrativa (um futuro no qual uma multiplicidade de imagens e sons, ainda reunidos sob a alcunha cinema, desempenharia um ou mais papeis) encontra, na época pós-moderna, uma espécie de interdito. Analisando essa mesma época (a passagem dos anos 1970 para os 1980), Jameson identificou certa obsessão pela ideia de "fim" (e pelo prefixo "pós"), em que os "prognósticos, catastróficos ou redencionistas, a respeito do futuro foram substituídos por decretos sobre o fim disto ou daquilo" (JAMESON, 1996: 27).

Estabelecida a crise do conceito de futuro, o cinema, de maneiras as mais diversas, buscou criar uma espécie de duplicação de seu próprio passado: ao invés da novidade e da invenção (eminentemente moderno), os filmes procuravam retornar a outros filmes anteriores, ao mesmo tempo a recriá-los e a ignorar qualquer problematização que poderia surgir desse retorno ao "banco de imagens" (eminentemente pós-moderno) no qual a história humana parecia haver se convertido. Um cinema que foi acusado de "nostalgia" (JAMESON, 1985: 20) por sua insistência em reciclar o passado - ou, para usarmos uma expressão anacrônica, em encenar um passado reloaded. Este é o diagnóstico que Jameson associa ao "capitalismo tardio" (JAMESON, 1996), momento atrelado às ideias de especulação financeira, aceleração e instabilidade. Com sua por vezes atordoante multiplicidade de possibilidades - a grande maioria delas ligadas à ansiedade frente à iminência da catástrofe (climática, econômica etc.) —, o capitalismo tardio (doravante "neoliberalismo") parece ser um dos principais responsáveis pela "morte do futuro", bem como pela série de mudanças no cinema, sejam as de ordem ontológica (relativas ao estatuto das imagens no mundo) ou, mais recentemente, de ordem técnica (que culminaram nas imagens digitais).

Um dos autores a perceber de maneira mais clara essas mudanças foi Serge Daney. "A rampa (bis)", escrito em 1981, assinala a chegada de uma nova fase do cinema, para além do clássico e do moderno, em que as imagens "deslizam umas sobre as outras" (DANEY, 2007: 233). Ao invés de "revelarem" algo antes oculto (como no cinema clássico) ou de denunciarem a falsidade envolvida nessa suposta revelação (como no cinema moderno), as imagens estariam então mais propensas a se relacionar com um repertório prévio do que com o próprio mundo, e passariam a se voltar sobre elas próprias, em um movimento algo elíptico e autorreferente, em muitos sentidos próximo à arte barroca, o que leva Daney a encerrar seu texto com uma pergunta: "Então, o barroco?" (DANEY, 2007: 234).

A partir de "A rampa (bis)" podemos identificar, já no final dos anos 1970, uma primeira mudança ontológica nas imagens do cinema. Entre outros desdobramentos possíveis a partir dos autores em questão, podemos pensar que essa "nova fase" das imagens é também, conforme o Lyotard de A condição pós-moderna (LYOTARD, 2009), 
refratária ao metarrelato e sua tendência à universalidade e a comportar longos períodos históricos sob uma ótica totalizante. Como que para marcar essa impossibilidade do metarrelato, o cinema estadunidense - tão pródigo em narrativas de grande escala realizou uma espécie de último épico, um filme cuja primeira versão (nunca lançada comercialmente) tinha a duração de 325 minutos e que, quando lançado, em 1980 (com 219 minutos), levou a United Artists à bancarrota e interrompeu, ao menos por alguns anos, a carreira de seu diretor: trata-se de O portal do paraíso. ${ }^{2}$

Por sua duração (mais de três horas de projeção), seu tamanho (elevadas cifras de orçamento, muitos figurantes etc.) e sua ambição (tematizar a violenta colonização da terra e a memória da guerra civil), O portal do paraíso aspirava a uma qualidade que chamaremos de épica, que Rosenfeld define como uma "expressão monológica", que comporta "certa distância entre o narrador e o mundo narrado", em uma "uma atitude distanciada e objetiva" (ROSENFELD, 1985: 25). Nada nessa definição parece concordar com o conceito de imagens que "deslizam umas sobre as outras", o que revela certo anacronismo do filme: uma entre tantas razões que lhe impuseram o fracasso comercial e - pelo menos até seu restauro digital e relançamento, em 2012 - o desprezo de grande parte da crítica especializada.

Se, no início dos anos 1980, o cinema ainda não havia atingido seu fim, o mesmo não pode ser dito do gênero épico, que possui características específicas: em poucas palavras, uma suposta objetividade da narrativa, baseada na separação cartesiana entre sujeito e objeto - já bastante questionada por comentadores de textos filosóficos, bem como pela teoria do cinema e pelos próprios filmes do cinema moderno. O cinema épico parece irremediavelmente ligado ao passado e, pior, ao fracasso comercial: vide os exemplos dos anos 1960 (como o Cleópatra de Joseph L. Mankiewicz). Se no contemporâneo ainda podemos chamar alguns filmes de "clássicos" (como os de Clint Eastwood, por exemplo), o épico se transformou em impossibilidade ou anacronismo.

Ao pensarmos em termos de mise-en-scène, o distanciamento exigido pelo épico pode ser atingido de diferentes maneiras, sendo a mais óbvia talvez o plano aberto, muito presente em $O$ portal do paraíso, seja para destacar as paisagens naturais, seja para mostrar a quantidade de figurantes reunidos em cenas de conjunto. $O$ filme de Cimino lança mão do distanciamento (na composição da imagem) para retratar tanto os grandes espaços (a geografia montanhosa do oeste dos EUA) quanto os movimentos históricos (as ações de uma coletividade humana). Assim, vemos uma recorrência de grandes grupos de pessoas - em celebrações ou assembleias - , que demonstra uma

${ }^{2}$ Sobre os percalços da produção e do lançamento do filme, ver: BACH, Steven. Final Cut: Art, Money, and Ego in the Making of "Heaven's Gate", the Film That Sank United Artists. New York: Newmarket Press, 1999. 
tendência em entender a história não como a soma de ímpetos individuais (uma das marcas do pensamento neoliberal), mas sim como uma complexa e constante construção coletiva (cujas forças principais serão didaticamente individualizadas a partir das convenções do melodrama e identificadas em alguns dos personagens centrais).

De qualquer maneira, o fracasso do filme de Cimino demonstrou como suas premissas pareciam ultrapassadas em 1981. A grande história, como todo metarrelato, parecia perder força, enquanto a petite histoire ganhava cada vez mais espaço. Em uma tabela explicativa sobre as diferenças entre o modernismo e o pós-modernismo - em que este parece superior àquele - Hassan coloca a grand histoire em relação ao primeiro e a petite histoire em relação ao último (apud HARVEY, 1992: 48).

À época do lançamento de $O$ portal do paraíso, o neoliberalismo ditava as condutas dos governos da Inglaterra (Thatcher) e dos EUA (Reagan). Na era dos yuppies (os empreendedores do mercado financeiro, com sua ambição de enriquecer o mais depressa possível), os portais da grande histoire - uma história entendida como narrativa histórica coletiva - pareciam fechados. Com o fracasso do filme, esse tipo de narrativa dificilmente voltaria a encontrar lugar no cinema contemporâneo. Além disso, O portal do paraíso ficaria também conhecido como uma espécie de ponto final na Nova Hollywood, período em que a indústria estadunidense concedeu liberdade inédita a alguns realizadores, em uma espécie de ponto intermediário entre a politique des auteurs francesa e a grande indústria do entretenimento. Após o filme de Cimino, o controle dos filmes voltaria para as mãos dos produtores, que mais uma vez passavam a deter a palavra final sobre os projetos, um pouco como nas décadas de 1930 e 1940. A fase dos autores (Coppola, Friedkin, Scorsese) estava terminada.

E, se o épico cinematográfico parece chegar ao fim com O portal do paraíso, onde estaria seu início? Em Intolerância (Intolerance, D. W. Griffith, 1916), que atravessa quatro diferentes épocas históricas para elaborar uma lição moral: a "oposição entre o bom coração dos simples e a hipocrisia dos poderosos" (XAVIER, 1984: 68). Ao montar, de maneira alternada, quatro épocas distintas (a queda da Babilônia; a paixão de Cristo; a noite de São Bartolomeu - o massacre dos protestantes em 1572, na França; e um episódio contemporâneo), o filme de Griffith representa também o ápice das escolhas estéticas encontradas desde os curtas-metragens do realizador na American Biograph: um sistema de decupagem que busca certa objetividade (uma narração onisciente e oculta), porém nunca desassociada da emoção dos personagens centrais, de sua subjetividade (que acaba por conduzir o interesse da narração).

Griffith, que nunca abriu mão das convenções do melodrama, fez esse equilíbrio entre objetividade e subjetividade pender ao (ou, em alguns casos extremos, perder-se no) sentimentalismo. Em Intolerância, esse equilíbrio é comprometido por uma radical 
simplificação, em que "a complexidade do social reduz-se à luta entre caridade e intolerância” (XAVIER, 1984: 62). Desde então, grandes painéis abundaram no cinema. Mas, para nosso argumento, importa menos a extensão das narrativas ou a quantidade de personagens ou a multiplicidade de pontos de vista, e sim uma tendência à representação de forças históricas coletivas - critério sob o qual mesmo Intolerância parece não ser suficientemente épico.

Após $O$ portal do paraíso, surgiram ainda outras tentativas de um cinema mais próximo ao épico, mas que parecem sempre enfraquecer os vínculos entre as narrativas individuais e a grande narrativa histórica. Como exemplos, Gangues de Nova York (Gangs of New York, Martin Scorsese, 2002) ou Sangue negro (There will be blood, Paul Thomas Anderson, 2007) tentam recuperar uma perspectiva de como o metarrelato ecoa nas narrativas individuais (e vice-versa). Outros filmes mostraram como o épico também pode aparecer como paródia - Gladiador (Gladiator, Ridley Scott, 2000) — ou pastiche - Alexandre (Alexander, Oliver Stone, 2004). Assim, arriscamos dizer que o filme de Cimino seria ao mesmo tempo o primeiro (o mais bem acabado) e o último exemplo do que poderia ser o épico cinematográfico nos moldes de Hollywood.

O metarrelato exigido pelo épico parece uma demanda irreconciliável com o neoliberalismo, que entende a construção da história não como produto coletivo, mas como a soma de esforços individuais. Na produção de imagens, a muito comemorada democratização dos meios de produção proporcionada pelas tecnologias digitais funcionou também como um estímulo ao surgimento de narrativas mais pessoais e por vezes íntimas (filmes com testemunhos privados e imagens cotidianas). Nesse processo, mesmo o longa-metragem viu surgirem obras de grande interesse - para ficarmos em apenas um exemplo, lembraremos Tarnation (Jonathan Caouette, 2003).

Nesse novo momento, o plano aberto se torna menos presente. Seja pela relação mais íntima entre o cineasta e seus objetos, seja pelo tamanho menor das telas em que os filmes são visualizados, que pede uma distância mais próxima entre a câmera e seus assuntos. A partir do final dos anos 1970 e do começo dos anos 1980, nota-se um gradual abandono do plano aberto, seja nas produções mainstream ou nas amadoras. O plano geral se tornou cada vez mais confinado a uma função trivial — informar a localização espacial dos elementos da cena - e parece, hoje, salvo em alguns cineastas, esvaziado de suas funções menos denotativas.

A morte do cinema talvez tenha sido exageradamente decretada, mas o plano geral (ao menos como usado por Cimino em O portal do paraíso) encontra-se, no mínimo, subutilizado. 


\section{Ontologia das imagens digitais}

Além do fim do épico, encontramos outras características nas imagens do neoliberalismo. Uma das mais debatidas é a suposta perda do caráter de índice entre a imagem e seu referente. Sobre isso, Elsaesser aposta na permanência (e pertinência) do pensamento de André Bazin:

Notando que o cinema mudaria para sempre nossos conceitos de tempo, linearidade e sucessão temporal, [Bazin] nos faz reconsiderar o que é o cinema a partir do que ele foi, revisitando seu passado como que para ampliar ainda mais - e não interditar - o futuro desse mesmo passado, ao mesmo tempo em que interpreta o presente de maneira a não apenas conectá-lo ao passado mas também a,

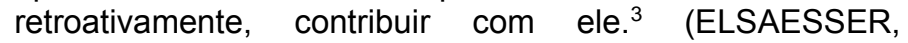
2011: 379, tradução nossa)

Nesse trecho, a obra do crítico francês é pensada como capaz não apenas de ajudar a compreender o cinema dos anos 1940 e 1950 (o cinema moderno), mas também a época contemporânea. Para isso, um texto central é Ontologia da imagem fotográfica, em que Bazin define a fotografia como "a satisfação completa do nosso afã de ilusão por uma reprodução mecânica da qual o homem se achava excluído". E, logo depois, conclui que a solução para esse afã por realismo "não estava no resultado, mas na gênese." (BAZIN, 1985: 21).

Ora, é justamente em sua gênese que encontramos uma das diferenças fundamentais entre os processos digital e analógico. Mesmo concordando com Elsaesser e com a pertinência do pensamento de Bazin na atualidade, é preciso partir do texto Ontologia da imagem fotográfica para testarmos uma outra ontologia, ligada às imagens digitais.

Comecemos pelas diferenças. No processo analógico de captura de imagem, a luz atinge uma superfície fotossensível e deixa um rastro (ou, nos termos da semiologia, um índice). Após a revelação, este rastro passa a evocar o momento original do encontro entre luz e película - é no instante desse contato, desse encontro, que se "faz" a imagem analógica.

No caso do digital, quando a luz atinge a superfície fotossensível, ela é convertida em informação (ou, nos termos da semiologia, em signo): depois, essa informação precisará ser armazenada e, mais tarde, decodificada para se transformar novamente em imagem. Nesse caso, a imagem se "faz" no momento em que é convertida para outra

\footnotetext{
${ }^{3}$ No original: "Sensing that cinema would change forever our idea of time, linearity, and temporal succession, he extends what cinema is by making us reconsider what it was, revisiting its past so as to open once more this past's own future, rather than foreclose it, while interpreting the present in a way that not only links it to the past but also retroactively contributes to it."
} 
linguagem. Trata-se menos de uma "captura" e mais de uma "tradução". Uma vez transformada em código de informação, torna-se muito mais fácil intervir em determinadas características da imagem, tais como saturação, contraste, brilho etc. Tal facilidade deve-se a essas características serem, também elas, armazenadas como informação.

É óbvio que os processos analógicos sempre possibilitaram tais intervenções, como nas trucagens e na criação de efeitos. ${ }^{4} \mathrm{O}$ que está em questão não é exatamente a maior facilidade na manipulação da imagem digital, mas o fato de essa manipulação poder ser levada praticamente ao infinito. Para pensarmos em um exemplo ligado ao cinema e relacionado à criação de efeitos visuais, o diretor Peter Jackson possui uma vasta coleção de itens de memorabilia e, em seu acervo, encontra-se um modelo articulado de metal, de aproximadamente 30 centímetros de altura, utilizado nas filmagens do King Kong de 1933 (King Kong, Merian C. Cooper; Ernest B. Schoedsack). ${ }^{5}$ Ao dirigir sua própria versão do filme (King Kong, Peter Jackson, 2005), Jackson não usou nada parecido com a miniatura de seu acervo para criar o gorila gigante: em vez de lançar mão de um modelo articulado (ou de qualquer outro recurso material), o filme de 2005 desenvolveu o personagem em CGI (Computer-Generated Imagery). Não mais passível de ser "colecionado" (como no caso do modelo de seu antecessor), o novo King Kong pode apenas ser "arquivado" em um mídia digital. A partir desse exemplo, percebemos que a trucagem analógica depende de uma materialidade em contato com a superfície fotossensível e que há sempre a necessidade de certos materiais ou procedimentos específicos para cada resultado desejado, sendo eles totalmente distintos uns dos outros, de acordo com o que se deseja como resultado final.

Por outro lado, o tratamento das imagens digitais utiliza um processo sempre idêntico, independentemente do resultado desejado: uma operação matemática a partir do código que armazena a informação. Uma operação que não depende mais de uma materialidade, mas de uma virtualidade, do conhecimento de como cada alteração no código corresponde a cada resultado final.

De maneira ainda mais explícita, no caso do analógico, é possível haver materiais para alguns resultados e não para outros. No caso do digital, por outro lado, como todos os procedimentos são igualmente possíveis, basta saber como operar o código de informação. Assim, no limite, uma imagem digital equivale a todas as suas variações. Nesse mesmo sentido, Gaudreault e Marion afirmam que, "no reino do digital, registrar

\footnotetext{
${ }^{4}$ Sobre a manipulação de imagens fotográficas analógicas, ver: FINEMAN, Mia. Faking It: Manipulated Photography Before Photoshop. New York: The Metropolitan Museum of Art, 2012.

${ }_{5}^{5}$ Conforme relato em entrevista a Adam Savage: "Peter Jackson's Original King Kong Stop-Motion Armature". Disponível em: https://www.youtube.com/watch?v=elbYsYqZxPQ. Acesso em: 24 jul. 2019.
} 
o real já é, simultaneamente, reconstruí-lo". Mais ainda, seria uma "literalização" ou "essencialização" desse ato (GAUDREAULT; MARION, 2016: 77). Em outra passagem, os autores afirmam que o digital "ontologiza a trucagem" (GAUDREAULT; MARION, 2016: 169).

Assim, a relação com as imagens (predominantemente digitais) se mostra cada vez menos referencial, mas, ao mesmo tempo, verifica-se um curioso efeito, que lembra as críticas de Jameson ao cinema "nostálgico" que busca reconstruir (ou simular) o passado: é bastante comum que aplicativos de fotos tenham a opção de filtros digitais que imitam a textura de imagens analógicas - película fotográfica (de vários tipos), desenho, pintura etc. Novamente, busca-se a construção de um passado reloaded. Mas, por trás da aparência vintage, há apenas o acúmulo de um código sobre o outro: informação sobre informação, manipulação sobre manipulação. E se os rastros podiam se reproduzir em progressão aritmética; os códigos o fazem em progressão geométrica...

Essa quantidade acachapante de imagens pode colaborar, conforme Crary, para a sensação de aceleração que permeia o contemporâneo. O autor afirma que a “aceleração não é simplesmente uma sucessão linear de inovações, na qual cada item obsoleto é substituído por um novo. Cada substituição é sempre acompanhada por um aumento exponencial do número de escolhas e opções disponíveis." (CRARY, 2014: 52). O "aumento exponencial do número de escolhas", no caso da manipulação de imagens, existe em todas as etapas: captura, tratamento e consumo.

Apesar do fim do futuro ser alardeado desde o final da década de 1970, é necessário outro marco histórico na transição do analógico ao digital - outro momento decisivo para as imagens do neoliberalismo. Um marco que estabelece uma mudança não na história das tecnologias, mas na das sensibilidades. Nesse sentido, lembramos o ataque terrorista que causou a queda das torres gêmeas do World Trade Center em Nova York, em 11 de setembro de 2001, evento transmitido ao vivo para todo o mundo.

$O$ ataque às torres gêmeas foi divulgado de maneira mais ou menos "homogênea" em todo o mundo e, nas imagens do evento, ainda restava uma ideia de rastro, de vínculo direto com os eventos ali registrados. Esse índice, de maneira um tanto paradoxal, estava recuperado (e talvez pela última vez) justamente pelo caráter, digamos, inconcebível do evento em si, apesar (ou por causa) de seu caráter realista. Concordando com Bazin, mas indo em outra direção, chegamos ao conceito de um realismo ambíguo: mesmo a mais inconcebível imagem (a menos banal) pode ter seu efeito de realismo intensificado. Acredita-se no que se quer acreditar. O realismo é menos estético que psicológico:

A polêmica quanto ao realismo na arte provém desse mal- 
entendido, dessa confusão entre o estético e o psicológico, entre o verdadeiro realismo, que implica imprimir a significação a um só tempo concreta e essencial do mundo, e o pseudorrealismo (...), que se contenta com a ilusão das formas. (BAZIN, 1985: 21)

Bazin nos faz pensar na questão da descrença como menos conectada à gênese da imagem (se analógica ou digital, rastro ou código) do que à sua montagem, sua relação com outras imagens. Essa ideia está mais desenvolvida no texto Montagem proibida, em que o autor afirma, sobre o curta $O$ balão vermelho (Le ballon rouge, Albert Lamorisse, 1956), que "a ilusão é criada, como na prestidigitação, a partir da realidade. Ela é concreta e não resulta dos prolongamentos virtuais da montagem" (BAZIN, 1985: 57). Ainda nesse texto, Bazin estabelece não uma oposição tacanha entre realidade e ilusão, mas uma espécie de interdependência entre esses dois polos, como se uma surgisse (e dependesse) da outra. Encontramos, aí, uma pista para compreender o estatuto das imagens no neoliberalismo, ao mesmo tempo banalizadas e supervalorizadas, ao mesmo tempo desacreditadas e provas da evidência de um fato.

Assim, no evento do ataque às torres gêmeas, grande parte do efeito de real das imagens se deu não só por seu caráter documental, mas também por seu caráter de encenação. Diferentemente da grande maioria dos ataques terroristas - que ocorrem de surpresa e assim possibilitam registros posteriores ao evento em si - a queda das torres gêmeas ofereceu (pelo fato de serem duas torres) a chance de uma repetição, ao mesmo tempo uma documentação do presente (a segunda torre sendo atingida por um avião) e uma representação do passado (de como a primeira torre havia sido atingida por um avião). Após a torre norte ser atingida, câmeras e aparelhos de registro de toda espécie foram rapidamente ligadas e estavam a registrar o fogo e a fumaça quando, dezessete minutos depois do primeiro impacto, um outro avião atingiu a torre sul. Nesse instante, ocorre o efeito aqui apontado: temos uma imagem que seria a marca de nossa época, uma imagem que funciona ao mesmo tempo como realidade e ilusão. Concluise que, apesar das facilidades da manipulação das imagens digitais e da descrença inerente a esse processo (devido ao descolamento da imagem de seu referencial material), ainda é possível obter uma impressão de realismo, um efeito de real.

Desde 2001, todo ano, durante a noite de 11 de setembro, dois feixes verticais de luz são ligados em Manhattan, em alusão às torres gêmeas. O evento, chamado "Tribute in Light", recria a presença das torres a partir da substância mais diáfana: a luz. Um signo luminoso atravessa o ar e as nuvens, como se marcasse a qualidade também diáfana e efêmera das imagens digitais. Um simulacro das Twin Towers, a lembrar os limiares entre realidade e representação, fato e memória. A lembrar que a ontologia das imagens 
analógicas começou a desmoronar em 11 de setembro de 2001 e que as explosões dos ataques se fazem sentir desde então.

\title{
Potências do falso
}

Então, ao invés da busca do real, o elogio ao falso? Não exatamente. Em A imagemmovimento, Deleuze escreve que:

\begin{abstract}
Seria necessário poder afirmar que a imagem é objetiva quando a coisa ou o conjunto são vistos do ponto de vista de alguém que permanece exterior a esse conjunto. Trata-se de uma definição possível, mas exclusivamente nominal, negativa e provisória. Pois o que nos garante que o que inicialmente tomávamos como exterior ao conjunto não vai se revelar como lhe pertencendo? (DELEUZE, 1985: 95)
\end{abstract}

Eis o motivo da época pós-moderna impedir o épico cinematográfico. Os planos abertos de $O$ portal do paraíso nunca serão abertos o bastante: a câmera de Cimino nunca poderá estar em algum lugar "exterior ao conjunto" das coisas do mundo. A partir de Deleuze, é possível pensarmos a fadiga do cinema épico não mais a partir de um esvaziamento da história (ou pela impossibilidade do metarrelato, como queria Lyotard), mas por um excesso de imagens. A multiplicação de pontos de vista faz com que cada um deles se torne também um pouco mais efêmero.

Mais uma vez a partir de Deleuze, podemos recolocar a proposição de Daney, de que as imagens "deslizariam umas sobre as outras". Não apenas as imagens como também os pontos de vista passam a se deslocar uns sobre os outros, em um jogo no qual a hierarquia entre uma imagem e as demais termina por ser sempre provisória outra razão pela qual o ponto de vista objetivo exigido pelo épico parece impossível no contemporâneo. Para o autor de $A$ imagem-tempo, um dos filmes exemplares a respeito do deslocamento das imagens no mundo contemporâneo seria Verdades e mentiras ( $F$ for Fake, Orson Welles, 1973). O filme de Welles trabalha sobre pontos de vista incapazes de revelar qualquer pressuposta verdade ao criar imagens sempre provisórias, ora falhas (incompletas), ora falsas (não verdadeiras). No capítulo intitulado "As potências do falso", Deleuze coloca o cinema de Welles ao lado do pensamento de Nietzsche para identificar o esgotamento de um mundo tido como "verdadeiro":

[Welles] faz a imagem ficar sob o poder do falso. (...) Há um nietzscheanismo de Welles, como se ele tornasse a passar pelos principais pontos da crítica à verdade em Nietzsche: 0 "mundo verdadeiro" não existe e, se existisse, seria inacessível, não passível de evocação; e se fosse evocável, seria inútil, supérfluo. $O$ mundo verdadeiro supõe um "homem verídico", um homem que quer a verdade, mas tal homem tem estranhos móveis, como se ele escondesse em si outro homem. (DELEUZE, 1990: 168) 
Para exemplificar esse ponto, Deleuze volta a Verdades e mentiras e sua série de falsários: Elmyr de Hory (que criou quadros falsos assinados, entre outros, por Matisse e Modigliani), seu biógrafo, Clifford Irving (também autor de uma falsa biografia de Howard Hughes) e o próprio Welles (que termina por confessar ter deliberadamente enganado seu público durante o trecho final do filme). As imagens de Verdades e mentiras deslizam umas sobre as outras de maneira intensa: o filme é um tour de force de montagem que faz questão de mostrar, em vários momentos, Welles na sala de edição. Como se o realizador de Cidadão Kane aludisse ao ato de montar (manipular as imagens, conferindo a elas novos significados e usando-as para construir uma ilusão fílmica) como mais importante que o ato de filmar. Em outras palavras, trata-se de colocar a interpretação (a hermenêutica) como mais importante que a percepção (a fenomenologia).

Por todas essas razões, Verdades e mentiras, desde seu lançamento, tornou-se central para o debate a respeito do filme-ensaio, bem como da nova idade das imagens, como identificada por Daney. Em sua narrativa, o filme mostra, atrás de um falsário, outro falsário; atrás de uma imagem, em vez da verdade, apenas outra imagem. Assim, Welles cria uma espécie de dúvida incessante, que sempre questiona suas próprias bases e que pode ser, de maneira sumária, assim resumida: um relato afirma que certo quadro é falso; mas esse relato é, ele mesmo, também falso; isso torna o quadro menos falso?

Para resolver o caso, Deleuze volta a Nietzsche e cita a figura do "homem verídico", relacionando-o ao falsário. O filósofo francês coloca-os como se fossem as duas faces de uma mesma moeda:

Atrás do homem verídico há pois o falsário (...) e um está remetendo sempre ao outro. O perito em verdade abençoa os falsos Vermeer de Van Megeeren precisamente porque o falsário os fabricou conforme seus próprios critérios, os do perito. Em suma, o falsário não pode ser reduzido a um mero copiador, nem a um mentiroso, pois o que é falso não é apenas a cópia, mas já o modelo. (DELEUZE, 1990: 178)

Umberto Eco (2018: 249) também tratou da questão da falsidade e da mentira. Para o autor, "estar enganado não é exatamente mentir", sendo que "mentir é dizer o contrário daquilo que se pensa que é o caso". Assim, "dizer o falso é um problema alético - que tem a ver com a noção de aletheia, ou seja, de verdade", enquanto "mentir é um problema ético, moral".

Mas a questão colocada por Deleuze questiona e mesmo inviabiliza a taxonomia de Eco: como não mentir quando a própria noção de verdade (definida pelos peritos) pode ser alterada a qualquer instante (de acordo com os próprios peritos)? Talvez, de acordo 
com Eco, o filme de Welles possa escapar da acusação de mentira, mas nunca da de falsidade. Porém, para Deleuze, a questão moral deve ter seu sinal invertido: quão verdadeiros seriam os critérios do perito?

Verdades e mentiras (a tradução do título do filme de Welles) tornam-se elas mesmas escorregadias e passam a deslizar umas sobre as outras. Se as imagens digitais podem prescindir de um referente material, isso não faz delas algo necessariamente mentiroso, mas revela o que há de falso em toda imagem. Ao mesmo tempo, estabelece-se um infindável debate (algo como uma bolsa de apostas) sobre qual verdade (se alguma) estaria representada em uma imagem. Só podemos concluir que estamos presos a um mundo de aparências. E que a verdade possível (o realismo possível, se quisermos retomar Bazin) seria feito de encenações e simulacros. (E como poderia ser diferente?).

Ao tratar da fase estadunidense do realizador, Deleuze identifica em Fritz Lang outro criador de imagens falsas, um mestre das aparências:

O Lang americano torna-se o maior cineasta das aparências, das imagens falsas (...). Tudo é aparência, e no entanto esse novo estado transforma o sistema de julgamento, e não o suprime. Com efeito, a aparência é o que trai a si mesmo; os grandes momentos em Lang são aqueles em que uma personagem se trai. As aparências se traem, não porque dariam lugar a uma verdade mais profunda, mas simplesmente porque elas próprias se revelam como nãoverdadeiras. (DELEUZE, 1990: 169)

A descrença nas imagens digitais não se deve a uma verdade oculta que será, mais cedo ou mais tarde, revelada (essa revelação, Daney associou ao cinema clássico), mas à compreensão de que elas nada ocultam e, se o fazem, trata-se apenas de uma outra aparência (uma outra imagem, segundo Daney). As imagens não revelam a verdade, mas, no máximo, sua inexistência - ou, dito de outra maneira, a impossibilidade de qualquer verdade transcendente.

No contemporâneo, se a ideia de objetividade está comprometida a ponto de impossibilitar tanto o épico quanto a grande histoire, a única verdade possível é a imanência da própria imagem.

\section{Ainda mais um fim}

Um breve epílogo sobre como essa questão de verdades e mentiras está presente no neoliberalismo: as imagens que circulam nas redes sociais ou nos aplicativos de mensagens instantâneas se tornam verdade não por uma conexão com algum fato real, mas pelo veredito do grupo de "consumidores" dessa mesma imagem. Há, por um lado, a perda de um espaço social de debate, o que tem causado mais um alardeado fim, não 
mais o do cinema, mas o das democracias nos países ocidentais. ${ }^{6} \mathrm{O}$ neoliberalismo elimina os cidadãos (que participam de espaços coletivos de debate e decisão) e os transforma em consumidores, cada um satisfeito com sua verdade prêt-à-porter, reafirmada pelas imagens recebidas em seu aparelho portátil.

Nesse contexto, salta aos olhos um violento acirramento de uma disputa pelo realismo das imagens, em que cada um dos lados (normalmente organizados em polos binários) luta pela prerrogativa de definir, para cada imagem em questão, o que corresponderia à realidade e à ilusão. Dessa maneira, a crise das democracias ocidentais - outra consequência do neoliberalismo - não está distante de uma espécie de radical crise hermenêutica, em que uma imagem pode ser lida de uma maneira ou de outra, completamente distinta, dado o viés político-ideológico do receptor e a concordância de um grupo identificado com um idêntico espectro político-ideológico. A crise da verdade (a crise da imagem) padece hoje desse mesmo binarismo a separar, de um lado, a verdade e, do outro, a mentira. Porém, como vimos a partir dos autores aqui citados, esses dois lados podem se retroalimentar. A verdadeira disputa está em outro lugar, nos critérios que decidem entre verdade e mentira. Dito de maneira talvez um pouco mais pragmática, o que está em disputa é a decisão sobre quais imagens podem ser aceitas como factuais e quais necessitam ser "desmascaradas".

Busca-se o "homem verídico", como o entende Deleuze:

O homem verídico não quer finalmente nada mais que julgar a vida, ele exige um valor superior, e bem, em nome do qual poderá julgar; tem sede de julgar, vê na vida um mal, um erro a ser expiado: origem moral da noção de verdade. (DELEUZE, 1990: 168)

Talvez a crise das democracias seja a crise da verdade, questão intimamente ligada à questão das próprias imagens. Deleuze recapitula como se estabeleceu o vínculo entre as noções de "clássico", "verdade" e "ponto de vista":

O século XVII não foi a idade "clássica" do ideal da verdade, mas a idade barroca por excelência, (...) quando a verdade atravessava uma crise definitiva. Não se tratava mais de saber onde ficava o centro, o sol ou a terra, pois a primeira questão tornava-se: "Há, ou não, um centro qualquer?". Todos os centros, de gravidade, de equilíbrio, de força, de revolução, em suma, de configuração, desmoronavam. (DELEUZE, 1990: 175)

O autor fala de "uma restauração dos centros", ao custo "de uma mudança profunda, de uma grande evolução das ciências e das artes". E conclui: "Por um lado o centro se

\footnotetext{
${ }^{6}$ Ver: RUNCIMAN, David. Como a democracia chega ao fim. Tradução: Sergio Flaksman. São Paulo: Todavia, 2018.
} 
tornava puramente ótico, o ponto se tornava ponto de vista. As perspectivas ou projeções são o que não é nem verdade nem aparência." (DELEUZE, 1990: 175).

A crise desse "centro puramente ótico" (e a crise do "ideal clássico de verdade") é o que move tanto o texto de Daney como o filme de Welles. A partir daí, a pergunta "Então, o barroco?" passa a ressoar em um contexto histórico mais amplo. As imagens deslizam umas sobre as outras porque esse núcleo (o ideal de verdade) não mais existiria a atraílas umas para as outras, organizando-as segundo uma relação de forças prédeterminada. Atualmente, é o próprio jogo de forças, a própria relação entre as imagens que se encontram indeterminados.

Assim, parece óbvio que a grande narrativa histórica, como nos moldes de O portal do paraíso, tenha se tornado anacrônica. Mas, mesmo com a crise do ideal clássico de verdade, o realismo é possível.

Bazin ensina que o efeito de real na fotografia depende de uma parte da imagem que estaria para além das opções do fotógrafo, aquilo que escaparia ao seu controle. Daí seu projeto de valorizar obras cinematográficas que estejam abertas para eventos fora dessa área de controle. Mas Bazin também lembra que o realismo é um fator antes de tudo psicológico. Ou seja, é a gênese da imagem fotográfica que nos faz "acreditar" nesse realismo, e não uma suposta correlação entre a imagem e seu referencial material.

Nas imagens digitais, essa psicologia se altera, e a gênese da imagem nos faz "desconfiar" delas, mesmo que haja correlação entre a imagem e algum fato real. Tal característica, ao invés de contradizer a teoria de Bazin, parece, pelo contrário, endossar sua leitura do realismo como um estilo e como uma psicologia de recepção das imagens.

\section{Considerações finais}

O neoliberalismo é o pano de fundo de grande parte das mudanças abordadas neste artigo. Segundo Berardi, as novas relações econômicas e de trabalho mudaram a percepção comum do futuro:

Se os movimentos das finanças, da economia e da produção estão desconectados de qualquer elemento quantificável, de uma massa mais ou menos compacta e passível de avaliação de tempo de trabalho, então não é mais possível qualquer previsão, qualquer conhecimento confiável. E muito menos é possível acreditar na eficácia da ação humana. (BERARDI, 2019: 106)

Essa descrença na ação humana amplifica a sensação de catástrofe tão comum em nossa época e parece criar muito taxativos "fins": do cinema, da verdade, da democracia. Estamos vivendo em um período que faz lembrar o trecho de Deleuze sobre o século 
XVII, em que "os centros, de gravidade, de equilíbrio, de força, de revolução, em suma, de configuração, desmoronavam".

O neoliberalismo defende o fim de soluções coletivas, sendo que a "salvação" do futuro estaria no domínio da escolha individual. O tempo talvez mostre que, ao contrário do que imagina Berardi, o futuro não morreu (mas talvez tenha se transformado em uma espécie de bolsa de valores que responde aos anseios de uma maioria numérica da qual o próprio futuro se tornou refém). Refém do "homem verídico" que, ao emular a lógica da especulação financeira, acabou por recriar o futuro como um presente eternamente adiado.

Duas explosões deram início à queda das torres gêmeas do World Trade Center. As imagens digitais, por sua vez, parecem ter transformado o mundo em um território virtual e impalpável, talvez mesmo efêmero como um suspiro. Pois entre as explosões e o suspiro, nem o cinema nem as democracias ocidentais ainda chegaram a um final.

\section{Referências Bibliográficas}

BAZIN, André. O cinema: ensaios. Tradução: Eloisa Araújo Ribeiro. São Paulo: Brasiliense, 1985.

BERARDI, Franco. Depois do futuro. Tradução: Regina Silva. São Paulo: Ubu, 2019.

COONAN, Clifford. Greenaway anounces the death of cinema - and blames the remotecontrol zapper". The Independent, London, 10 out. 2007. Disponível em: www.independent.co.uk/news/world/asia/greenaway-announces-the-death-of-cinemaand-blames-the-remote-control-zapper-394546.html. Acesso em: 24 jun. 2019.

CRARY, Jonathan. 24/7 - capitalismo tardio e os fins do sono. Tradução: Joaquim Toledo Jr. São Paulo: Cosac Naify, 2014.

DANEY, Serge. A rampa (bis). In: DANEY, Serge. A rampa: Cahiers du Cinéma, 19701982. Tradução: Marcelo Rezende. São Paulo: Cosac \& Naify, 2007. p. 229-234.

DELEUZE, Gilles. A imagem-movimento: cinema 1. Tradução: Stella Senra. São Paulo: Brasiliense, 1985.

DELEUZE, Gilles. A imagem-tempo: cinema 2. Tradução: Eloisa de Araújo Ribeiro. São Paulo: Brasiliense, 1990.

DIXON, Wheeler Winston. Twenty-five reasons why it's all over. In: LEWIS, Jon (ed.). The end of cinema as we know it: american film in the nineties. New York: New York University Press, 2001. p. 356-366.

ECO, Umberto. Dizer o falso, mentir, falsificar. In: Nos ombros dos gigantes: escritos para La Milanesiana. Tradução: Eliana Aguiar. Rio de Janeiro: Record, 2018. p. 247-284.

ELSAESSER, Thomas. A Bazinian half-century. In: ANDREW, Dudley; JOUBERTLAURENCIN, Hervé (eds.). Opening Bazin: postwar film theory and its afterlife. Oxford: Oxford University Press, 2011. E-book. 
GAUDREAULT, André; MARION, Philippe. O fim do cinema?: uma mídia em crise na era digital. Tradução: Christian Pierre Kasper. Campinas: Papirus, 2016. (Coleção Campo Imagético).

HARVEY, David. A condição pós-moderna: uma pesquisa sobre as origens da mudança cultural. Tradução: Adail Ubirajara Sobral; Maria Stela Gonçalves. São Paulo: Loyola, 1992.

JAMESON, Fredric. Pós-modernidade e sociedade de consumo. Tradução: Vinicius Dantas. Novos Estudos CEBRAP, São Paulo, n. 12, p. 16-26, jun. 1985.

JAMESON. Fredric. Pós-modernismo: a lógica cultural do capitalismo tardio. Tradução: Maria Elisa Cevasco. São Paulo: Ática, 1996.

LYOTARD, Jean-François. A condição pós-moderna. Tradução: Ricardo Corrêa Barbosa. 12 ed. Rio de Janeiro: José Olympio, 2009.

ROSENFELD, Anatol. O teatro épico. São Paulo: Perspectiva, 1985.

XAVIER, Ismail. D. W. Griffith: o nascimento de um cinema. São Paulo: Brasiliense, 1984. 